\title{
Correction to: Pigment Epithelium-Derived Factor Improves Paracellular Blood-Brain Barrier Integrity in the Normal and Ischemic Mouse Brain
}

\author{
Arina Riabinska ${ }^{1,3}$ (D) Marietta Zille ${ }^{2,4} \mathbb{C} \cdot$ Menderes Yusuf Terzi ${ }^{1,5} \mathbb{E} \cdot$ Ryan Cordell $^{1} \cdot$ Melina Nieminen-Kelhä $^{1}$ (D) \\ Jan Klohs ${ }^{2,6,7}$ (i) Ana Luisa Piña ${ }^{1}$ (D)
}

Published online: 18 May 2020

(c) Springer Science+Business Media, LLC, part of Springer Nature 2020

\section{Correction to: Cellular and Molecular Neurobiology https://doi.org/10.1007/s10571-019-00770-9}

The original version of the article unfortunately contained an error in the unit of the protein concentrations under 'Stereotactic Intraparenchymal Injections' subsection in 'Methods' section.
The unit should be $\mathrm{ng} / \mu \mathrm{l}$ instead of $\mathrm{ng} / \mathrm{ml}$.

Therefore, the sentence should read as follows:

For the claudin-5 expression study, solutions with the following protein concentrations were prepared: $40 \mathrm{ng} / \mu \mathrm{l}$ VEGF (group VEGF alone), $40 \mathrm{ng} / \mu \mathrm{l}$ VEGF and $40 \mathrm{ng} / \mu \mathrm{l}$ PEDF (group VEGF:PEDF 1:1), and $40 \mathrm{ng} / \mu \mathrm{l}$ VEGF and 80 ng/ $\mu 1$ PEDF (group VEGF:PEDF 1:2).

The original article can be found online at https://doi.org/10.1007/ s10571-019-00770-9.

Ana Luisa Piña

ana-luisa.pina@charite.de

1 Department of Neurosurgery, Experimental Neurosurgery/ BCRT, Charite-Universitätsmedizin Berlin, Campus Mitte, Chariteplatz 1/Virchowweg 21, Aschheim-Zondek-Haus 03-003, 10117 Berlin, Germany

2 Department of Experimental Neurology, Charité-Universitätsmedizin Berlin, Berlin, Germany

3 Department of Internal Medicine, Medical Clinic I, University Hospital of Cologne, Cologne, Germany

4 Institute for Experimental and Clinical Pharmacology and Toxicology, University of Lübeck, Lübeck, Germany

5 Department of Medical Biology, Hatay Mustafa Kemal University, Antakya, Hatay, Turkey

6 Institute for Biomedical Engineering, ETH and University of Zurich, Zurich, Switzerland

7 Neuroscience Center Zurich, University of Zurich and ETH Zurich, Zurich, Switzerland 
Accordingly, the caption of Fig. 1 should be as follows:
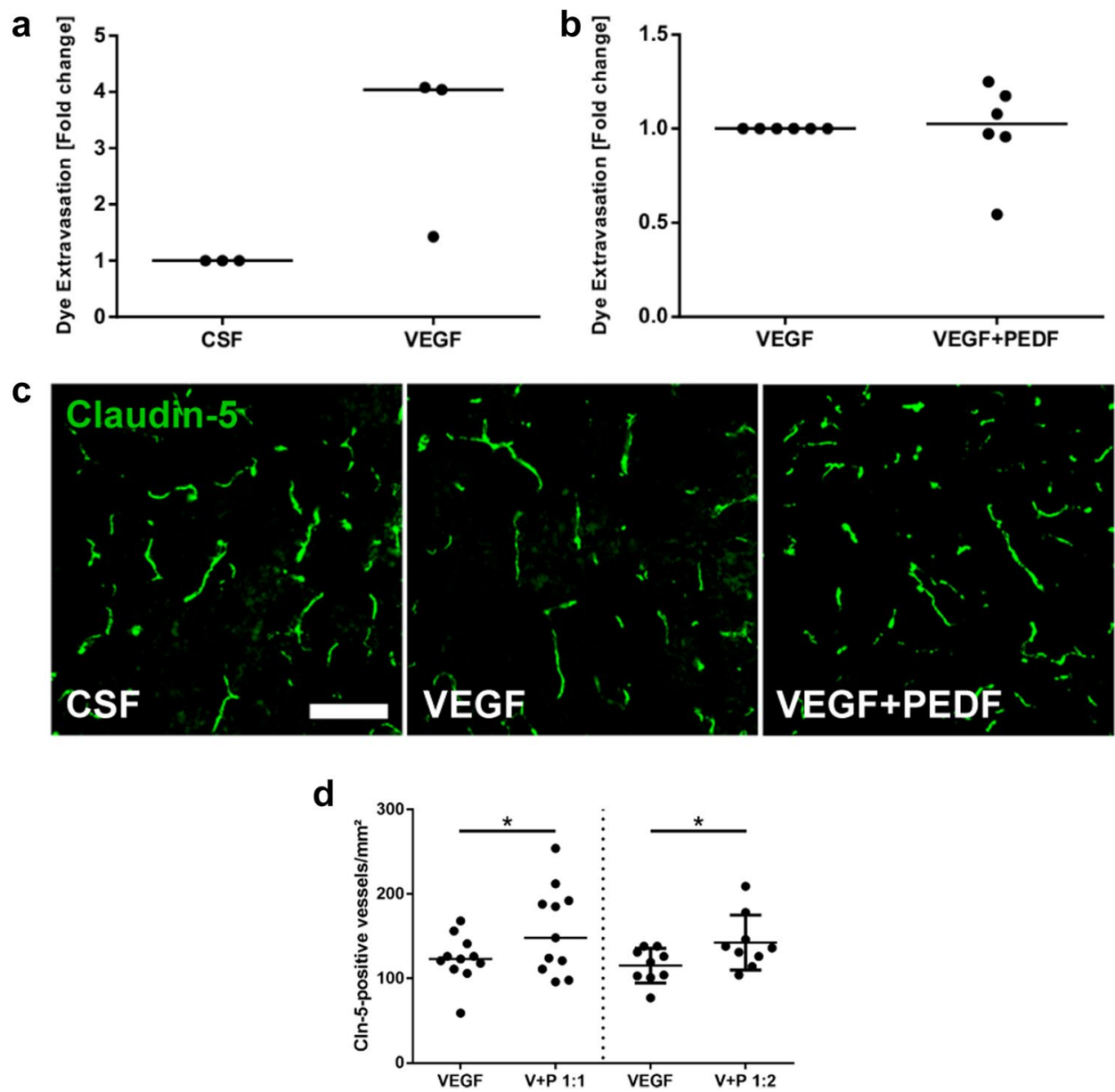

Fig. 1 The Co-injection of PEDF after VEGF-induced hyperpermeability reduces the paracellular blood-brain barrier disruption. a We wanted to confirm that VEGF induces hyperpermeability in the brain. Therefore, we administered intraparenchymal injection of $40 \mathrm{ng} / \mu \mathrm{l} \mathrm{VEGF}$ or CSF to the brain. VEGF did not significantly induce the transcellular extravasation of Evans Blue (expressed as the fold change to CSF, $n=3$ ). However, we recognize that the sample size was likely not large enough to show statistical significance. b Compared to VEGF alone $(40 \mathrm{ng} / \mu \mathrm{l})$, the coadministration of PEDF $(40 \mathrm{ng} / \mu \mathrm{l})$ did not change the Evans Blue extravasation $(n=6)$. c
Shown are representative pictures from the claudin-5 (Cln-5) stained brain samples in mice receiving an intraparenchymal injection of CSF, VEGF, or VEGF + PEDF. Scale bar $=100 \mu \mathrm{m}$. d The number of claudin-5-immunoreactive vessels significantly increased after the VEGF + PEDF (40 ng/ $\mu \mathrm{l}$ VEGF and $40 \mathrm{ng} / \mu \mathrm{l}$ PEDF for VEGF:PEDF $1: 1, n=11 ; 40 \mathrm{ng} / \mu \mathrm{l}$ VEGF and $80 \mathrm{ng} / \mu \mathrm{l}$ PEDF for VEGF:PEDF 1:2, $n=9$ ) compared to the $40 \mathrm{ng} / \mu \mathrm{l}$ VEGF-only treatment, indicating an improved paracellular BBB integrity. The data are represented as medians, except for the amount of claudin-5-immunoreactive vessels in VEGF + PEDF 1:2 that is presented as mean \pm SD, $* p<0.05$

Publisher's Note Springer Nature remains neutral with regard to jurisdictional claims in published maps and institutional affiliations. 